\title{
Arbor
}

\section{Mujeres pintoras del siglo XX}

\section{Carmen Rocamora}

Arbor CLXVIII, 663 (Marzo 2001), 321-331 pp.

Intentamos recoger en este artículo la dificultad de la mujer para ser reconocida por su valía intrínseca, en una sociedad que ha mirado siempre la prevalencia del hombre, para alcanzar puestos de responsabilidad, triunfos en el orden intelectual y, éxitos (a veces inmerecidos) en el mundo del Arte.

El nuevo siglo es el de la valoración de la Mujer. Quizá muchas de mi generación no lleguemos a verlo, pero una cosa es segura, solo faltan ayudas sencillas y fáciles otorgar, (educación, cultura, jornadas partidas, guarderías en su propio trabajo, incentivos económicos), para que triunfe en su profesión y al mismo tiempo "dé vida», a nuevos seres, para conseguir esa paridad tan deseada.

Es un hecho potencial en la actualidad, pero real con el paso el tiempo... Es una carrera imparable, donde no se vislumbra la meta ni el fin.

Yo me he limitado a seleccionar de forma subjetiva un grupo de mujeres pintoras que rompieron los moldes de su momento. Ellas avanzaron por un camino lleno de espinas, trabas y zancadillas... Pero supieron seguir adelante, basándose en su fuerza creativa, y en la seguridad personal de la valía de su trabajo.

Desde mi condición de mujer, ha sido un privilegio poder elogiarlas e impulsarlas en la medida de mis fuerzas.

Su triunfo ó su fracaso vital no tiene importancia. Su obra, que prevalecerá sobre el tiempo y el espacio, es su verdadero éxito. El sentimiento, la estética, el alma femenina que han dejado en sus telas, les da su enorme talla personal, aunque muchos, por miedo, por recelo, por egolatría ó por haber gozado de mayores patrocinios y apoyaturas, no quieran reconocerlo... 


\section{Introducción}

Alguna vez he dicho, no me acuerdo donde, que el pasado s.XX devolvió a la mujer su protagonismo, tanto en el mundo del arte como en el de las ideas.

El Impresionismo fue ya, en este sentido, tan avanzado, tan objetivo y tan valiente intelectualmente, que saltándose las reglas machistas de la época supo incorporar a sus filas a dos mujeres, valorándolas por sí mismas y dejando que algunos de sus grandes maestros se viesen influidos por ellas. Me refiero, naturalmente a Berthe de Morrisot y a Mary Casssat.

\section{Berthe de Morrisot}

Contrajo matrimonio con Eugene Manet, hermano del gran autor Edouard Manet, siendo primero la discípula de éste, luego su modelo preferida y finalmente su cuñada. Paul Valéry retrata su personalidad con estas palabras: «Representar en el lienzo sus experiencias, era para ella como si fuese una función natural y necesaria, ligada a su régimen vital... dejaba el pincel, volvía a retomarlo, lo mismo que viene, se esfuma y vuelve a nosotros un pensamiento»...

$\mathrm{Su}$ figura es desconocida para muchos y para otros considerada como una Impresionista de segunda fila. Sin embargo creo que ha llegado la hora de reivindicar su importancia, ya que su obra fue tan lograda y llena de belleza como la del mejor impresionista, no solo por su colorido, sino por la captación de la luz y de la atmósfera... producto, todo ello, quizá, quien sabe, por esa condición de mujer...

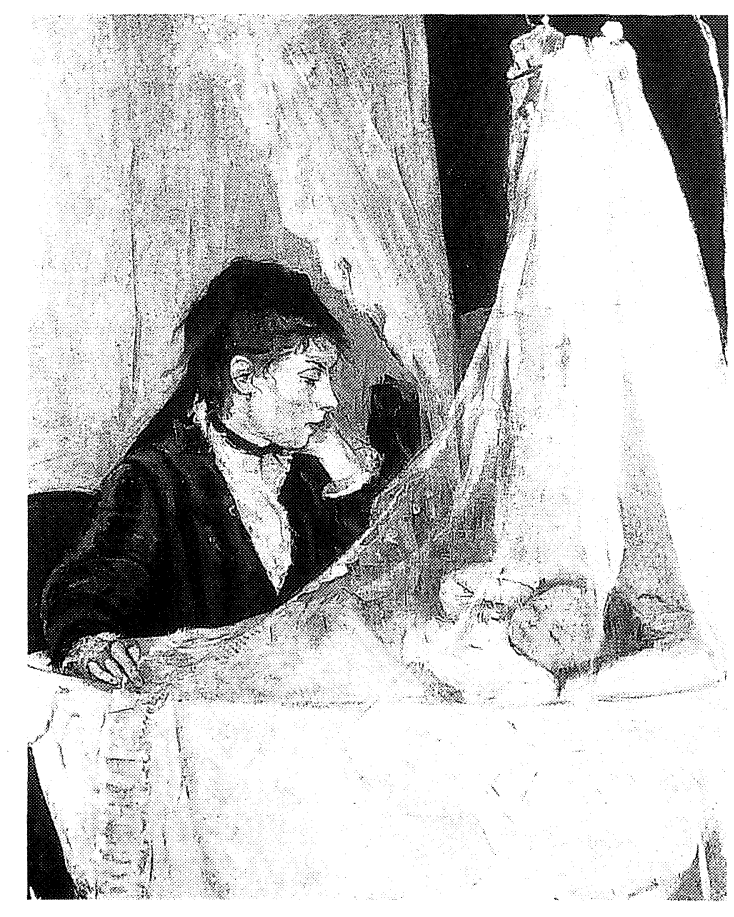

BERTHE MORISOT. «El niño en la cuna». Louvre. París. 


\section{Mujeres pintoras del siglo XX}

\section{Mary Cassat}

Nacida en Pittsbur, de padre francés no solo fue admirada por Degas, quien dijo de ella: «He aquí alguien que siente como yo», sino del merchante Durant-Ruel, quien le abrió las puertas de la Primera Exposición de Impresionistas, llevada a cabo en sus salones....

Fue amiga de otra gran mujer, la esposa del coleccionista Havenmayer, aconsejando a ésta en la compra de obras de gran importancia, hasta el punto de ser considerada como la gran impulsora del Impresionismo, en los EEUU, donde el arte, era en aquel momento, por decirlo de alguna manera, inexistente.

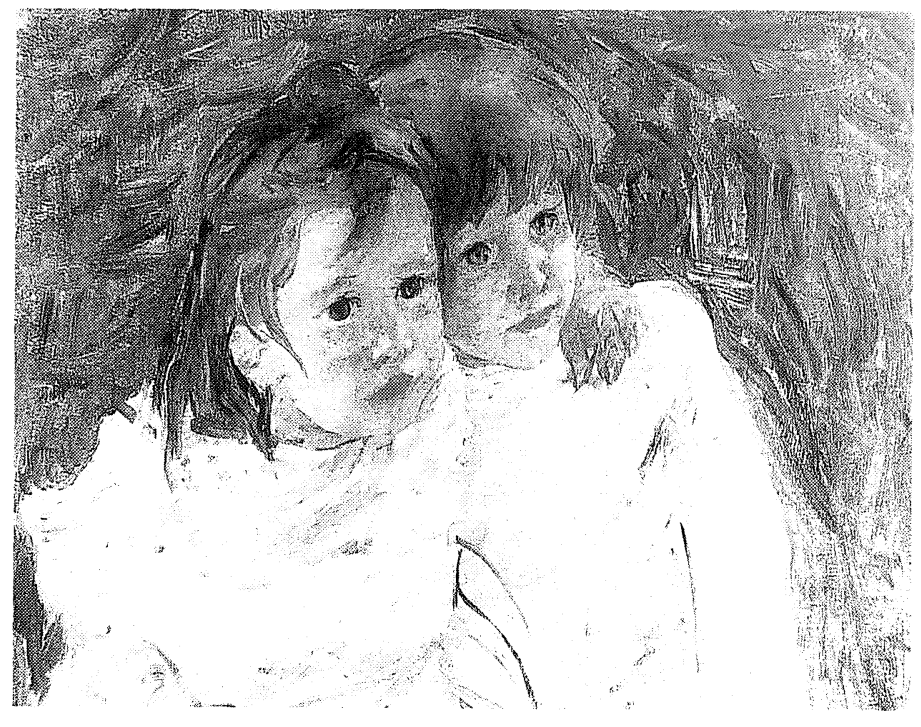

MARY CASSAT. «Las hermanas».

\section{Marie Blanchard}

Ya, antes de nacer, María Gutierrez-Cueto, había sido marcada por un destino trágico y negativo. Llegó al mundo con una doble desviación de la columna, con curvatura posterior y lateral, debido a la caída de su madre embarazada, al intentar subir a un coche de caballos.

Aquella niña contrahecha, perdida en sí misma, triste y solitaria no encontró consuelo en una madre altiva incapaz de aportar más que frialdad a aquel hogar necesitado de estímulo y consuelo.

Creció entre las risas sarcásticas de sus compañeros de clase, crueles y burlones ante su deformidad y, una sensación de conmiseración y de lástima por parte de sus familiares y seres queridos.

Solo su padre, hombre culto dotado para la pintura, supo comprender que aquella vida, inútil para la dicha y el amor, había de ser estimulada, y creó para ella un horizonte de esperanza. Aplaudía sus intentos de co- 
piar reproducciones de los grandes museos y le incitó a la pintura poniéndole profesores que sirvieran de ayuda a su posible vocación.

María huyó de Santander, su tierra natal, buscando en París los últimos restos del Impresionismo que tanto había admirado. Pero el París que le recibió había cambiado. Braque, Picasso y Juan Gris estaban desarrollando su Cubismo analítico y Apolllinaire habia publicado su libro: «Les peintres cubistes».

María regresó a España permaneciendo entre Madrid y Salamanca, consiguiendo ser profesora titular de la Escuela Normal de esta ciudad. Pero aquella bruja mítica de las que las gentes apartaban su mirada con gesto de repulsión, abandonó para siempre España en el 1917 y volvió a Paris para encerrarse en la vida mísera de los estudios y ateliers de la calle Maine.

Su incipiente admiración por Juan Gris, se convirtió en amistad profunda y de su mano entró de lleno en l'Ecole de París.

Su comunión con el cubismo era ya perfecta. De ella decía Jean Cassou: «La grandeza de su espíritu nunca será suficientemente elogiada, pues posee un universo de amor y de piedad, capaz de comprender que la

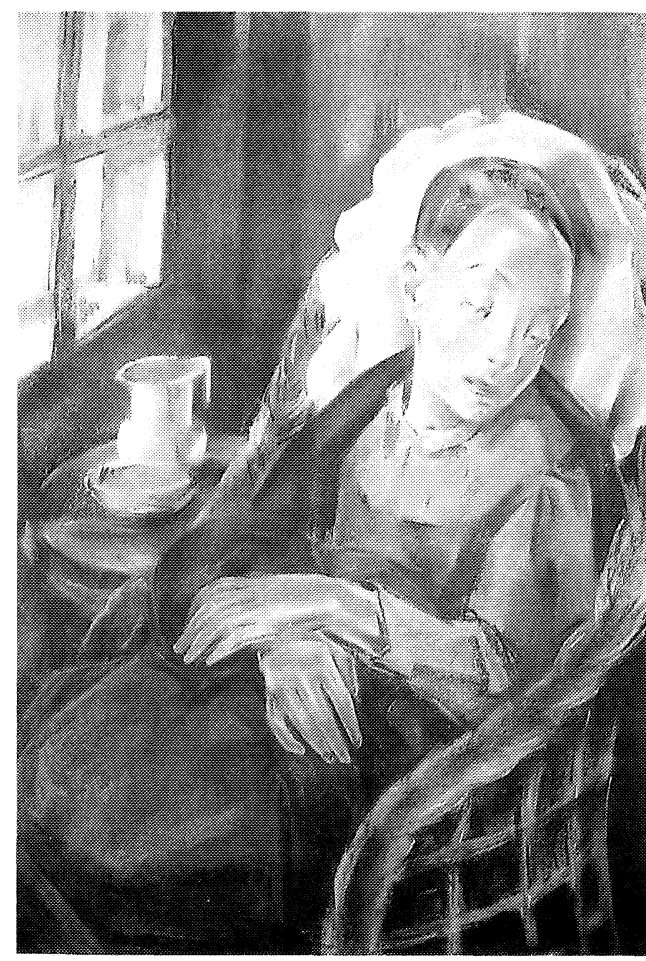

MARIE BLANCHARD. «La convaleciente».

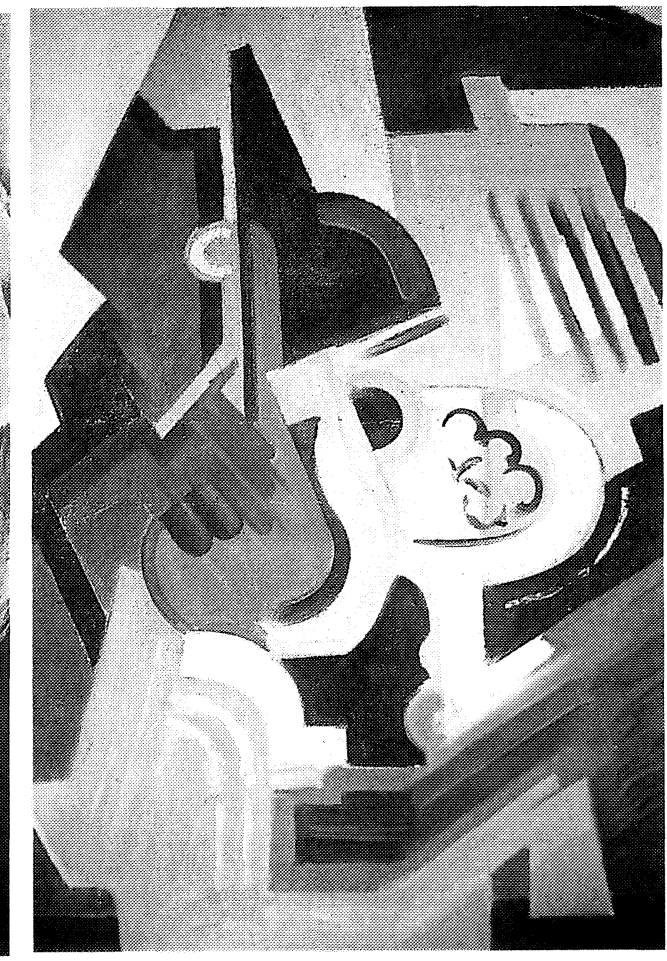

MARIE BLANCHARD. «Naturaleza muerta». 
emoción más profunda, no consigue expresarse sino bajo el control de la razón clarividente».

Por aquel entonces participó en el Salón de Otoño con «la Premiere Communiante», lo que mereció la siguiente opinión del crítico Vauxcelle: «Cuadro singular, de un poderoso carácter, pintado con un ciencia consumada».

Pero la artista, acostumbrada a crecerse ante la dificultad, demostró también su capacidad de no dormirse ante el éxito, y, renunció a aquella pintura que le había sido revelada para volver a sus orígenes de auténtica raíz española.

Federico García Lorca, la admiró sin conocerla, dedicándole un precioso artículo lleno de respeto y emoción. Su pintura llegó a ser comparada con la de Vazquez Diaz ó Valdés Leal... Pero la muerte de su gran Migo Juan Gris y el ingreso en el Convento de su joven discípula Isabelle Riviere , constituyeron un choque anímico excesivo para la pintora. A partir de ese momento, su vida se fué consumiendo en un claroscuro de éxito y de dolor.

...Hasta que en un atardecer de primavera de 1932, se fue, sin que nadie se enterase, sin ruido y sin importancia, como mueren los grandes artistas, cansada de su combate personal contra su propia figura y contra un mundo, que le fue siempre hostil...

Me voy referir ahora a otro grupo de pintoras actuales, no relacionadas entre sí, y difícilmente encasilladas en ningún grupo pictórico. $\mathrm{Me}$ gustaría mencionarlas fugazmente, por el simple hecho de que su pintura, deslumbra al espectador, y, también porque a lo largo de mi vida, he tenido el honor de conocerlas y hacer una crítica de su obra. Son: María José Chapatte, Ana María Serrano, Pilar Domínguez Toscano, Angelina Contreras Lopez de Ayala y Mercedes Gómez de Pablos.

\section{María José Chapatte}

Sus composiciones son escenas vivas captadas en el borroso cristal de un espejo imaginario. Sus figuras aparecen como visiones arrancadas al sueño, en medio de un sentimiento de ansiedad intangible.

Los seres que aparecen en sus cuadros, nunca pueden ser retratos de personas determinadas. Son producto de una imaginación que surge fantasmal salvada del dolor del tiempo... son sombras del huracán de su delirio imaginativo, encontradas un día en su irreprimible pensamiento...

La humanidad, ha creado un estilo de vida artificial, falsificado, insincero y sin alegrías. Si volvemos los ojos alrededor nuestro, encontramos el predominio de la tristeza en unos seres cuyas horas grises, se 
arrastran entre la monotonía y la vulgaridad. ¿Cómo no va a buscar el pensamiento creativo, huidas en su sueño para olvidar ese cerco de intolerables realidades?

María José Chapatte no es exactamente una pintora realista. Los fondos de sus telas están hechos a golpe de espátula, donde se adivina más que se ve lo que la pintora quiere mostrarnos, porque el contorno de las cosas no está configurado, sino apuntado en manchas de abstracción, entre las que asoman vagas sombras de seres que nadie conoce...

Ella no busca a su alrededor para pintar, encuentra en sí misma, los grandes espectáculos que su inteligencia crea, porque en su silencio, en su soledad está todo el mundo de sus sueños...

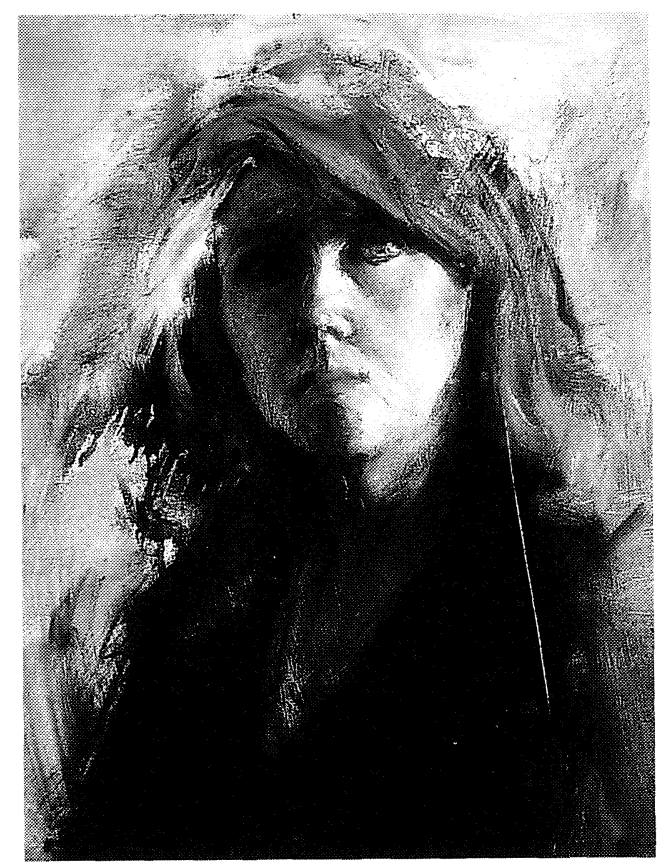

MARIA JOSÉ CHAPATTE. «Autorretrato».

\section{Ana María Serrano}

El Ganges al atardecer. Sus gentes intentan olvidar el mal endémico del hambre, la falta de higiene, y los tifones periódicos que se avecinan, con una violencia tal, que segarán las vidas de muchos de ellos. Se sumergen en sus aguas conjurando fuerzas superiores, mediante formulas y ritos diversos, para abrir una puerta a la esperanza. El río sagrado les aporta la idea de un mundo sobrenatural, con el que necesitan entrar en relación...

Ana María Serrano ha visitado Varanasiy, su recuerdo imborrable lo ha plasmado en unos cuadros sorprendentes, de difícil factura e imborrable mensaje.

Sus figuras, son hombres cargados con el vigor de los dioses y con la paciencia y aceptación de los seres inferiores. Los cuerpos, nos traen el recuerdo de héroes mitológicos de la Antigüedad, pero sus miradas nos confiesan las prácticas más groseras y brutales, a las que les llevan sus creencias fetichistas y totémicas.

La pintora ha contemplado los templos, situados a los lados del Ganges. Ellos son el centro de una doctrina que abarca, tanto la cosmogonía y la fi- 
losofía, como la medicina y el derecho de estos pueblos milenarios. Su alma ha quedado impregnada de esas figuras míticas: Indra, Agni, Rudra, Varuna, (Lluvia, Fuego, Calamidades, Cielo), y, a su vuelta nos ha traído un ejemplo de esas existencias, para hacernos meditar en la fugacidad de las cosas mundanas y en la promesa del paraíso ó nirvana de esas vidas que se mueven entre el sufrimiento y el hambre, para conseguir mediante reencarnaciones sucesivas, la paz, la perfección y el reposo definitivo...

\section{Pilar Domínguez Toscano}

Los Surrealistas, dedicaron sus vidas al análisis de los seres y de las cosas, hasta el punto de llegar a una esquematización de lo onírico. En España, si exceptuamos a Dalí y a Oscar Domínguez, ha habido muy pocos pintores que se hayan consagrado a esta fórmula de exteriorizar sus conflictos interiores.

Por ello, choca la aparición espontánea de la joven Doctora en Bellas Artes, Pilar Domínguez Toscano, con un Surrealismo visceral, que responde más a una sensación física, como el hambre o la sed que a un deseo de formalizar su pintura bajo ningún epígrafe o influencia.

Exterioriza su forma de ver el mundo, como una pesadilla materializada. Se asusta ante sus propios monstruos, quiere huir de ellos, pero no puede, porque son el testimonio auténtico de su propio pensamiento.

No se inspira en los maestros del Surrealismo. Su obra se asemeja cada día más a la de José Hernández, pero ella no lo sabe, simplemente,

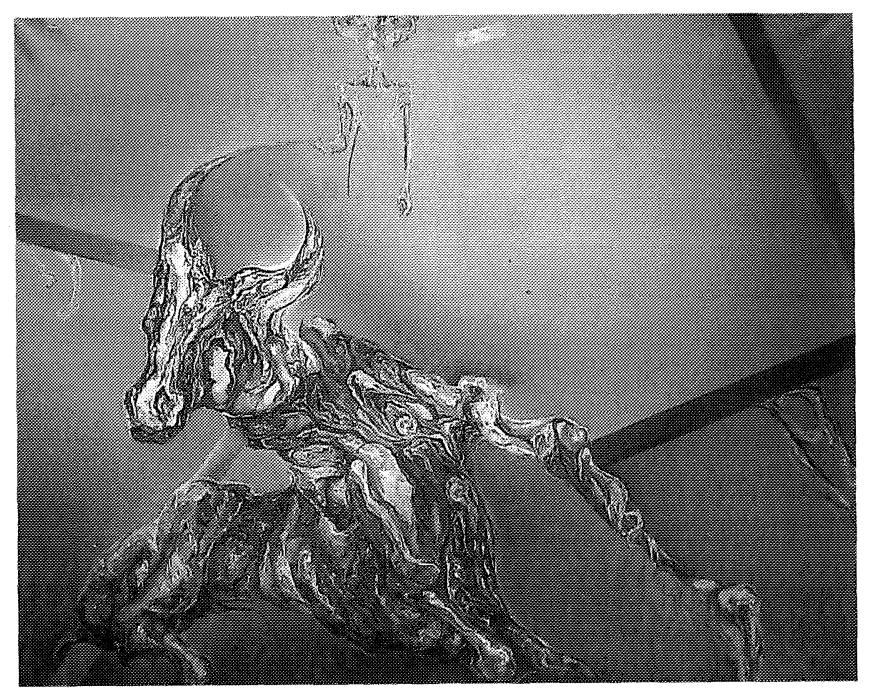

PILAR DOMINGUEZ TOSCANO. «La vaca rota». se levanta a las cuatro de la mañana porque necesita volcar su alma en una obra que oscila entre el éxtasis y el terror.

Sus formas deshumanizadas son viejos fantasmas del paraíso perdido de su infancia. Son las apariciones de sus noches de pesadilla, de las que intenta huir sin conseguirlo. ...Porque Pilar Domínguez Toscano, 
no ha comprendido todavía que en la desesperación de esas «Brujas de Salem» que ella representa, y, en las imágenes contradictorias y paranoicas con las que interpreta su comprensión de «Cien años de soledad», está la clave de su verdadera e intrínseca liberación.

\section{Angelina Contreras y López de Ayala}

Lleva en su paleta los verdes y azules del Mediterráneo. Trasplantada a Roma, cuando todavía era una niña, se le llenaron los ojos de imágenes del mundo antiguo, de vestales de mármol, de desgastadas casas de la Plaza de España, de la Escalinata de Trinitá dei Monti y de los pintores bohemios del viejo callejón de la Vía Margutta...

Su padre, el Marqués de Lozoya, fue durante largo tiempo, Director de la Academia de España, y allí la pintora tomó contacto con el mundo que iba a ser su vida, donde lo desconocido le abriría, entre las penas de la vida, un fantástico camino de esperanza.

Su madre, Constanza Lopez de Ayala fue una mujer singular, de una bondad inigualable y una sencillez infinita. Estuvo inmersa durante toda su existencia en ese ambiente literario y culto que acabo de describir, por ello, en 1986, muerto ya su marido, publicó un libro titulado: «Fábula, poesía, prosa», en el que con una belleza de sentimientos propia de su grandeza de espíritu, nos fue narrando los recuerdos de su vida en Ibiza, Roma, Segovia, lugares en los que quedó prendido su espíritu, porque en ellos habían transcurrido esos momentos de felicidad, que ella llenó de

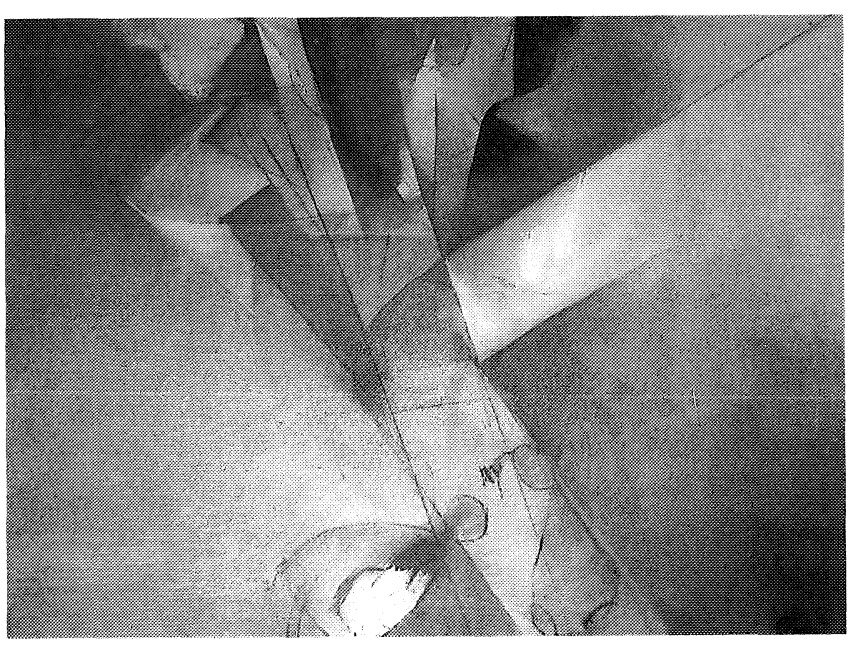

ANGELINA CONTRERAS Y LÓPEZ DE AYALA. «Sin título». luz con el señorío de su viejo linaje.

Angelina es de esas personas que no permiten que la vida «les gane la partida». Lucha con el corazón y la cabeza, aplicando la ilusión contra la dificultad ...y a veces, después del esfuerzo y el cansancio de una tarde, cuando mira un cuadro terminado, creo que consigue la felicidad, esa satisfacción 
que da la vida y que nada tiene que ver con la frivolidad que nos rodea, porque es el impulso que afianza el espíritu y la personalidad.

Cada día va imponiéndose deberes, obligaciones que ella cree que consigue con la ayuda del azar, cuando en realidad, lo debe todo a esa forma suya de afrontar la vida isin dejarla pasar!..

$\mathrm{Su}$ obra es revolucionaria y ante sus cuadros, se recibe una impresión de deslumbramiento, porque el espectador siente, en ese instante la impresión de asistir a un mundo en creación... Sin embargo, en otros momentos, triunfa el dramatismo de su paisaje natal, de la Castilla oscura de ocres infinitos, en los que todavía resuenan los ecos de nombres como Unamuno y Machado...

La pintora conoce, como decía Maurois, que no puede edificarse el porvenir en el desprecio del pasado, por ello, reforma y conserva, trabajando sin destruir, porque su experiencia vital le ha enseñado que no hay libertad sin seguridad, ni seguridad sin unidad, y su obra, tocada de sutileza e ingenio, consigue llegar a un equilibrio feliz.

Mientras tanto su existencia asciende por una pendiente escarpada, flanqueada por precipicios sobre los que nunca podrá descansar. Cada minuto es un inicio, cada día una lucha...

$\mathrm{Y}$ así en ese difícil juego, Angelina gana la partida, porque posee algo tan definitivo y escaso como el talento, que como decía Montequieu: «Es un don que Dios nos hace en secreto y que nosotros revelamos sin saberlo». Ella es como Disraeli, «el antiguo espíritu de la primavera, siempre renaciente, como símbolo de todo lo que se puede conseguir en un universo hostil, con la larga y profunda juventud del corazón»...

\section{Mercedes Gómez de Pablos}

El esfuerzo sobrehumano que tiene que realizar la mujer par conseguir el éxito, en esta sociedad presidida por el triunfalismo del hombre, es mil veces mayor, que el que tendría que hacer un varón, nacido, criado y apoyado desde todos los sectores de la vida pública para ese fin.

Por ello, cuando aparece una excepción a esta regla general y surge una mujer que rompe los moldes de una sociedad hostil, es para mí un honor, desde mi condición de mujer, admirar su fuerza, valorar su creatividad y dar testimonio de su trabajo, porque ha llegado al triunfo, aceptando desde un principio su reto, como deber cotidiano y primordial.

La pintura de Gómez de Pabios, es la meditación autónoma del color. En ella no es el dibujo el que da la orden al cuadro, sino el trazo continuo, el que produce el resultado final en la disposición de la luz. 
Es el arte, que adentrándose en ese espectáculo estético de la creación, es capaz de emular al ser superior, materializando lo espiritual hasta hacerlo palpable, en un acto volitivo que equipara a la mujer, mediante el ejercicio de su pensamiento y su capacidad de imitación, a la omnipotencia de un Dios en acción...

La selección de estas mujeres tiene un carácter meramente subjetivo. Podríamos citar muchas más, que, basándose en la dificultad como principio vital, creciéndose ante ella, no durmiéndose en el éxito, si alguna vez llegaran a alcanzarlo, luchan día a día por conseguir el reconocimiento de

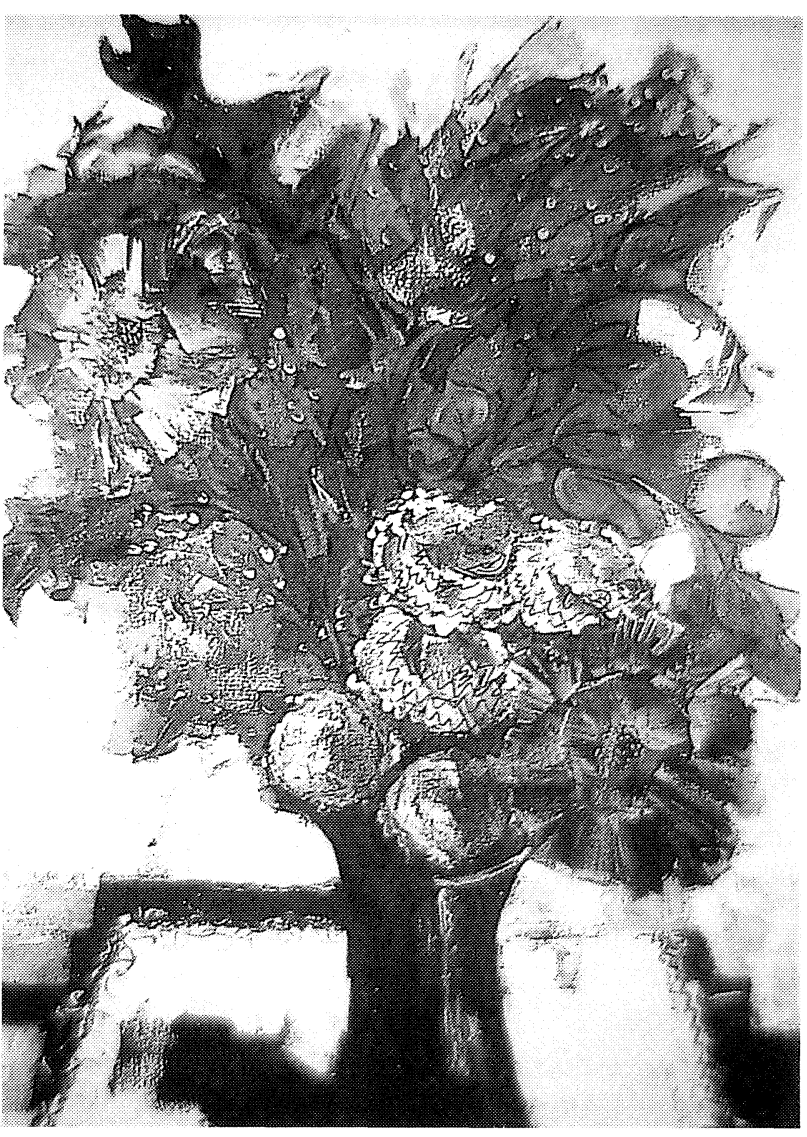

MERCEDES GÓMEZ DE PABLOS. «Naturaleza muerta». los demás.

A pesar de todo, aún hoy nos movemos en un momento de incertidumbre, de enormes esfuerzos, frente a grandes trabas y de mujeres extraordinarias que consiguen saltar al mundo de la valoración y del reconocimiento.

Lo que ellas intentan es alcanzar la gloria y conseguir la sabiduría. Para lo primero, hacen suya aquella frase de Maurois, que dice: «La mayor parte de los seres tiene que estar conquistando y reconquistando incesantemente a los demás, pues éstos no se ofrecen a ellos sin presentar combate»... Pero al mismo tiempo no olvidan, y así lo demuestran incansablemente, el contrapunto que nos ofrece la frase de Séneca: «Si me ofreciesen la sabiduría, con la condición de guardarla par mí, sin comunicarla a nadie, no la querría para nada»...

Colosal definición de estas mujeres que consiguen detener el tiempo en un instante, porque la belleza que crean, que transmiten, procede directamente de su propia belleza interior... 


\section{Mujeres pintoras del siglo XX}

\section{Bibliografía}

1 FroukJe HoEKstra. «Impresionism». Grange Books. London .1994.

2 «Musée d'Orsay. Chefs-dóeuvre impressionnistes et post -impresionnistes.» Editions de la Réunion des Muséees Nationaux et Thames and Hudson. Londres. 1993.

3 Maurice Serullaz. «La pintura impresionista». Ediciones Garriga. S.A. Barcelona. 1962.

4 A. M. CAMPOY. «María Blanchard». Editorial Gavar. Madrid. 1981.

5 CARMen RocAmora. "Lo fugaz y lo eterno de la pintura Contemporánea». C.R.G. Madrid .1990.

6 CARmen Rocamora. «Los nuevos dioses de la pintura actual». C.R.G. Madrid. 1991. 